\title{
LA PREECLAMPSIA
}

Forma única de hipertensión que se da en el embarazo.

Par: Dr. Manrique Vega Salana, Médica Cúdiga: II840
Dra. Zaida Patricia Pérez Rodríguez, Médicu Códiga: II76|

a incidencia es de un 5 a 7\%, típicamente en primíparas, a partir de la segunda mitad del embarazo, definiéndose como: HTA más proteinuria, y síntomas asociados como edema generalizados ( aunque estos no son criterios diagnóstico) síntomas visuales, cefalea, dolor epigástrico.

En ausencia de proteinuria, si la paciente sufre HTA asociada a trombocitopenia, alteración de función hepática, edema pulmonar, alteraciones neurológicas o visuales, confirma el diagnóstico.

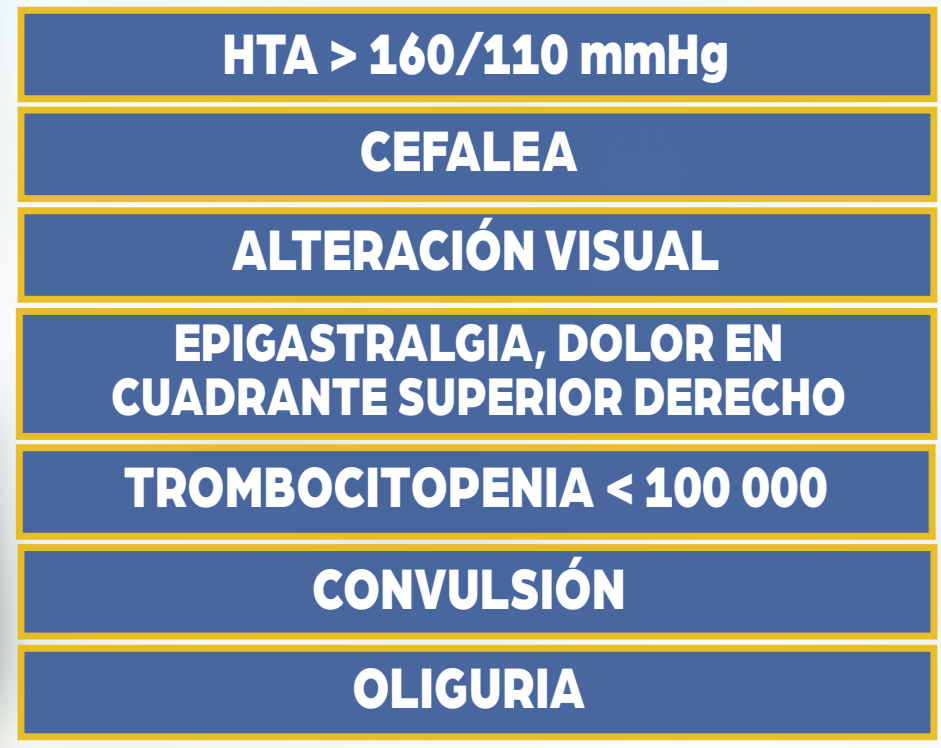

MARCADA ELEVACIÓN DE TRANSAMINASAS

\section{RCIU}

ELEVACIÓN DE LA CREATININA SÉRICA

EDEMA PULMONAR

\section{FACTORES DE RIESGO}

Tanto para la hipertensión gestacional, como para la preeclampsia, las siguientes condiciones, se han visto asociadas.

- Nuliparidad

- Antecedente de HTA gestacional, en embarazo anterior o en el actual

- Antecedente de preeclampsia en embarazo anterior

- Antecedentes familiares de preeclampsia

- Embarazo múltiple

- IMC elevado > $35 \mathrm{~kg} / \mathrm{m} 2$ al inicio del embarazo

- Ganancia exagerada de peso en el embarazo

- Edad materna extrema

El antecedente de preeclampsia en embarazo anterior multiplica por 7 el riesgo de volver a padecer esta enfermedad, y por 9 el riesgo de presentar HTA gestacional. Este riesgo será mas importante, mientras mas precoz se haga el diagnostico en el embarazo anterior, y puede presentarse con mayor gravedad y mas precozmente en la siguiente gestación.

La nuliparidad incrementa el riesgo 3 veces. La primiparidad es sin duda un factor de riesgo, pero cabe señalar que la primipaternidad, es lo que representa un verdadero riesgo, por esto las multíparas tienen riesgo de preeclampsia cuando cambian de pareja. Esto se apoya en la hipótesis de la fisio patología de una respuesta inmunológica exagerada, y que el riesgo de preeclamsia se incremente cuando hay breve exposición al semen paterno antes de la concepción.

Se debe destacar que el tabaquismo materno disminuye el riesgo de preeclampsia. 


\section{Fisiopatología}

A grandes rasgos, se trata de una enfermedad endotelial sistémica, con vasoespasmo generalizado, cuyo foco patogénico es la placenta, por eso la cura definitiva es la interrupción del embarazo.

La etiología exacta es desconocida, aunque se sospecha que es multifactorial. (Tabla 4)

\section{Tabla 4. ETIOPATOGENIA Y FACTORES DE RIESGO PARA PREECLAMSIA}

$\begin{array}{lll} & \text { - Hipoperfusión. } \\ \text { - Enfermedad Placentaria } & \text { - } \text { Alteración Inmunológica. } \\ & \text { Creación de anticuerpos maternos } \\ & \text { contra antígenos fetales. }\end{array}$

- Sensibilidad vascular aumentada - Alteraciones Plasmáticas a efectos vasculares presores.

- Aumento de situación

- Lesión endotelial

- Factor genético

- Enfermedades preexistentes
- Alteración entre el balance de endoletinas, tromboxano A2 y prostaciclinas.

- Alteración en la síntesis y función del Oxido Nítrico.

- Herencia recesiva.

- Polimorfismo genético.

- Autoinmunes

- Vasculares(DM)

- Trastornos de coagulación

- HTA crónica, etc.
También, la placenta produce ciertas proteínas como, la Tirosina Kinasa 1, que entran en la circulación materna, se une al factor endotelial vascular de crecimiento, y al factor placentario similar al de crecimiento y causan disfunción endotelial. Es por esto que los niveles maternos de esta proteína se pueden utilizar como marcador, para pacientes con alto riesgo de padecer de preeclampsia y la severidad de la misma.

Por ende la disfunción endotelial parece ser el factor central o la vía común, en la patogenia de la preeclamsia.

También el imbalance (Figura1), entre el aumento en concentraciones de Tromboxano y disminución en Prostaciclinas, que tienen efectos antagónicos, es uno de los postulados de la patogenia de la preeclamsia, ya que estas sustancias deben encontrarse balanceadas para que el embarazo transcurra normal.

\section{FIGURA 1.}

\section{PROSTACICLINAS}

Disminuyen la vasoconstriccion, agregacion plaquetaria y la actividad uterina

Aumentan el fujo uteroplacentario

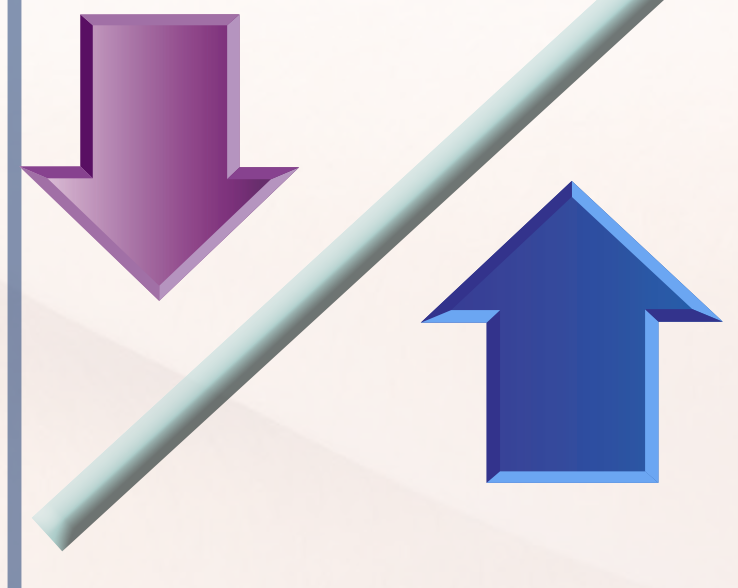

TROMBOXANO

Aumenta la vasoconstriccion, agregacion plaquetaria y actividad uterina

Disinuye el flujo utero placentario sanguíneo placentario pase de ser, de alta resistencia, a uno de baja resistencia, baja presión y alto flujo sanguíneo. Cuando esta invasión trofoblástica se realiza de manera anómala, se ha evidenciado una disminución en flujo sanguíneo uteroplacentario al finalizar en el embarazo, y por esto se relaciona con patologías como la preeclamsia y la RCIU. 


\section{¿Se puede predecir la preeclampsia?}

El método más utilizado es el Doppler de la arteria uterina, con una sensibilidad entre el 20 a $60 \%$, con un valor predictivo positivo de un 6 a $40 \%$. Sin embargo, no se debe utilizar como método de screening en todas las pacientes, sino en aquellas que están en alto riesgo de padecer dicha enfermedad. Es un método útil para detectar la preeclampsia de inicio temprano.

Asociado al Doppler, el uso de biomarcadores de función endotelial, como la Tirosina Kinasa 1 (SFlt-1), y de proteínas angiogénicas como: el Factor de crecimiento Placentario (PIGF), y el Factor de crecimiento vascular endotelial (VEGF). La alteración en las concentraciones de dichas sustancias, predice desde varias semanas antes, la aparición de la preeclampsia. Mientras más alta sea la concentración de SFIt-1, mayor la probabilidad de una preeclampsia de inicio temprano.

La hiperuricemia, también se ha utilizado como predictor de la preeclamsia en pacientes con HTA gestacional. El ácido úrico, es un indicador de: stress oxidativo, daño tisular y disfunción renal. Las pacientes con preeclampsia tienen una menor excreción del ácido úrico, debido a una reabsorción tubular proximal, por la isquemia. La hiperuricemia precede a la hipertensión y la proteinuria. El ácido úrico es el marcador que se ve más relacionado con la biopsia renal patológica en las pacientes con preeclamsia. Sin embargo, la hiperuricemia no es siempre sensible, y no es especifica en las pacientes con preeclamsia, además no tiene relación con el resultado perinatal, es por esto que la hiperuricemia, no es indicación de interrupción del embarazo en las pacientes con preeclampsia.

Sin embargo, hasta hoy en día, la FDA no ha aprobado un método de screening para la detección de preeclampsia, diferente a una adecuada historia clínica e identificar los factores de riesgo.

\section{Prevención de la Preeclampsia}

No existe una intervención que sea inequívocamente preventiva.

Para las mujeres con el antecedente de preeclamsia y parto pretérmino de 34 0/7, el inicio de aspirina de bajas dosis (60 a 150mg /día), iniciándose al final del 1 trimestre, es una recomendación.

Los suplementos de Vitaminas $E$ y $C$, no previenen la aparición de la preeclamsia.

No es necesario hacer dieta hiposódica, para prevenir la preeclampsia.

El reposo en cama, y la disminución en la actividad física no previene la preeclampsia ni sus complicaciones, y está asociado con mayor riesgo de trombosis.

\section{Manejo y tratamiento de la preeclamsia}

El objetivo principal del manejo de la paciente con hipertensión-preeclamsia, será mantener a la madre a salvo, y lograr un recién nacido maduro, que no necesite cuidados neonatales prolongados ni intensivos. La mayoría de las pacientes con el diagnostico de preeclampsia, tendrán un manejo ambulatorio, con un seguimiento, estricto para evaluar el bienestar maternofetal.

El tratamiento antihipertensivo está indicado cuando la TA es peligrosamente alta (mayor o igual a 140/90).

Los fármacos deberían controlar la hipertensión de manera rápida pero controlada, revierta la vaso-constricción, y que no afecte a la madre ni al feto. Los más utilizados en el embarazo se nombran en la tabla 5.

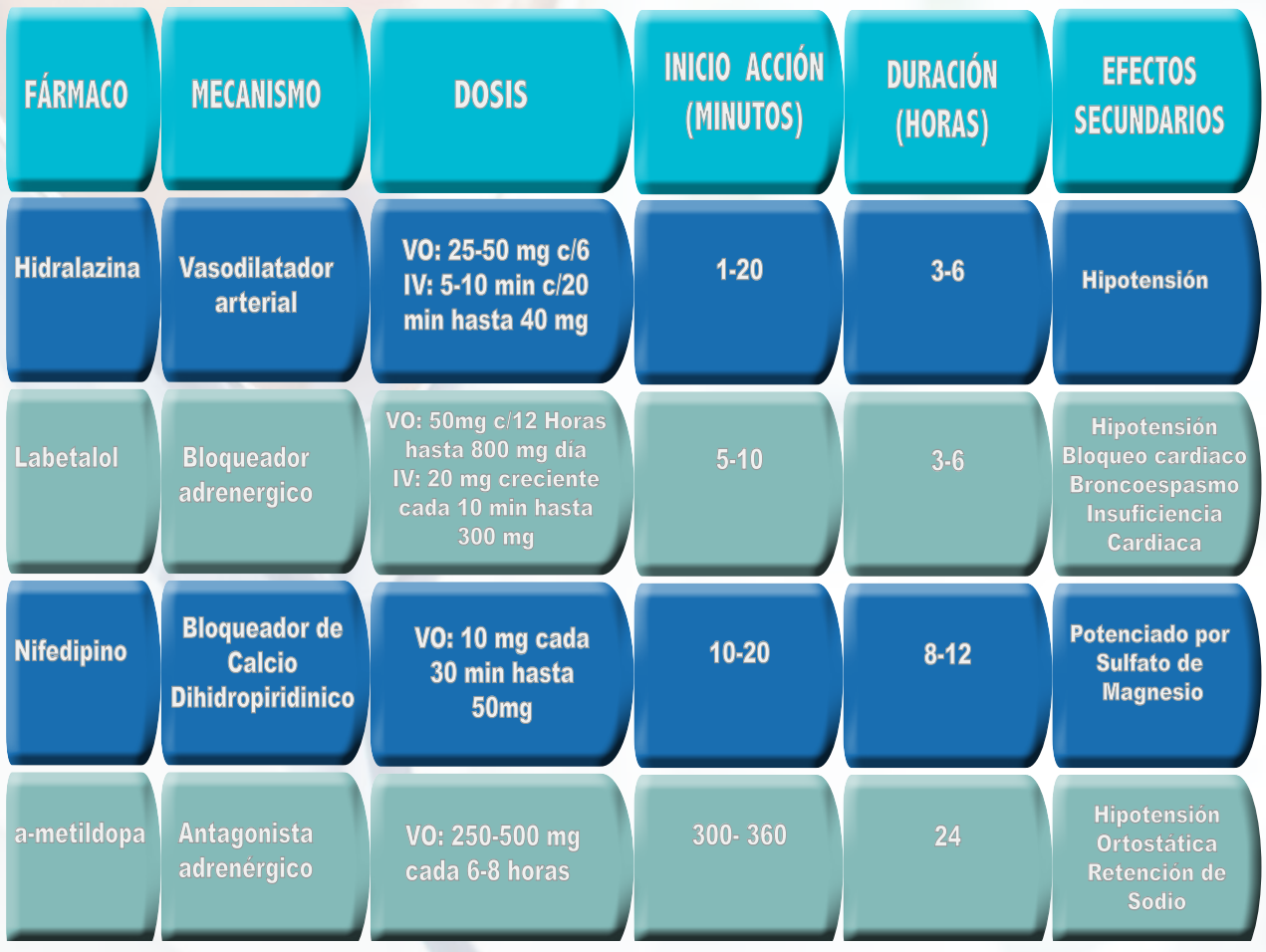

Ningún fármaco es superior a otro, ni actúan sobre el curso de la enfermedad, así que cualquiera puede ser indicado como primera opción, recomendándose que se utilice el que se cuenta con más experiencia.

\section{Están contraindicados:}

- Inhibidores de la enzima convertidora de angiotensina (IECAS), Antagonista de receptor de angiotensina II (ARA II), se han visto relacionados con aborto, óbito, fallo renal fetal y malformaciones.

- Atenolol, asociado a RCIU en tratamientos prolongados, en especial 
cuando se mantiene desde el primer trimestre.

- Diuréticos: disminuyen el volumen plasmático y flujo uteroplacentario.

- El tratamiento definitivo de la preeclampsia es la interrupción del embarazo, y el momento idóneo para hacerlo, depende los criterios de severidad asociados.

- Una paciente con hipertensión gestacional se puede interrumpir entre las 37 - 38 semanas.

- En general una paciente con preeclampsia sin criterios de severidad se puede inducir a las 37 semanas.

- $\quad$ Si la paciente se encuentra con preeclamsia con criterios de severidad, y la edad gestacional es igual o mayor a las 34 semanas, se indica interrumpir el embarazo al momento del diagnóstico.

- Si la edad gestacional es menor a las 34 semanas, dependiendo de la paciente se puede valorar un manejo expectante, con maduración pulmonar con esteroides, los cuales no aumentan la tensión arterial.

- Una de las complicaciones maternas a largo plazo, es el desarrollo de HTA crónica, en la paciente con antecedente de preeclampsia. También hubo un pequeño estudio donde se comprobó que hay disminución en la materia gris a nivel occipital en las mujeres que después de tener preeclampsia desarrollaron HTA crónica, sin embargo, el efecto de esta disminución de la materia gris aún necesita ser más estudiada.

\section{Eclampsia}

Es una complicación de la preeclampsia, que se presenta cuando la paciente tiene una convulsión tónico clónica generalizada, o presenta coma. Su incidencia ha disminuido por el tratamiento intensivo de la preeclampsia con criterios de severidad, ya que, se utiliza entre el arsenal terapéutico el sulfato de magnesio como neuro protector. Casi siempre la convulsión va precedida de algún pródromo, como la cefalea, fosfenos, acufenos, dolor epigástrico, náuseas, vómitos, reflejos osteotendinosos exagerados. Se ha propuesto que la causa de los síntomas a nivel de SNC, se debe a la trombosis microvascular, edema, hemorragia e hiperemia que presentan las pacientes con el antecedente de preeclampsia.

Cuando la eclampsia se presenta antes de las 32 semanas, usualmente, la convulsión es abrupta, y puede que estén ausentes otros síntomas y signos, como el edema y la proteinuria. De igual manera, muchas de las pacientes $(55 \%)$ que tienen una crisis en el posparto, nunca fueron diagnosticadas como preeclamticas durante el embarazo.

El sulfato de magnesio (MgSO4) es el tratamiento de referencia ante una crisis de eclampsia y para prevenir la misma. Se coloca $4 \mathrm{~g}$ en bolo IV a pasar en 30-60 min, seguido de una perfusión de 1-2 g/hr. Cuando se presenta una crisis de eclampsia, es indicación para la interrupción del embarazo, sin importar la edad gestacional.

Las complicaciones maternas, de una crisis de eclampsia incluyen: daño permanente al SNC, hemorragia intracraneal, insuficiencia renal y muerte.

En cuanto al feto la complicación más temida es la muerte neonatal, debida a: infarto placentario, RCIU, y desprendimiento prematuro de placenta normoincerta. Adicionalmente, este puede sufrir hipoxia, producto de las convulsiones maternas y dejar secuelas neurológicas. Sin duda la prematuridad, es la complicación más frecuente, con sus morbimortalidades asociadas.

Finalmente, las secuelas a largo plazo de haber sufrido HTA gestacional o preeclamsia, son el incremento en el riesgo de padecer:

- HTA crónica (5 veces si fue HTA gestacional,3 veces si fue preeclamsia, y 6 veces preeclampsia con criterios de severidad)

- DM (aumenta el riesgo 3.5 veces)

- Cardiopatía isquémica

- Enfermedad vascular cerebral

- Tromboembolismo venoso

\section{Conclusiones}

Es importante, que el medico que se enfrenta a la paciente embarazada hipertensa, tenga bien claro el tipo de paciente de la que se trata, ya que, estos trastornos pueden ir, desde una hipertensión crónica aislada hasta una preeclampsia eclampsia; y el manejo médico, farmacológico, seguimiento materno fetal, y el momento del parto difiere entre todos los diagnósticos diferenciales.

Los trastornos hipertensivos, siguen siendo gran causa de morbimortalidad materno fetal alrededor del mundo, siendo la preeclamsia y la eclampsia, los trastornos más relacionados con resultados adversos, ya que una hipertensión crónica leve, usualmente tiene poco efecto sobre el embarazo.

Ante cualquier tratamiento, hay que evaluar el riesgo-beneficio tanto materno como fetal. Este manejo debe ser individualizado, dependiendo de la gravedad del trastorno, edad gestacional, y estado del feto.

\section{Referencias bibliograficas:}

1.Akladios, Y. Gaudineau, A. Langer, B. Lecointre, L .\& Sananes, N. (2016) EMC Ginecologia - Obstetricia: Hipertensión Arterial y Embarazo, 52 (2) 1-15.

2.Arisanti, Y ( 2011) Poster Presentation / Pregnancy Hipertation: Comparison serum inhibinin A level, placenta inhibin A level and placenta inhibin A expression in severe pre-eclmsia/ eclamsia and normal pregnant women. 285

3.Bloom, S. Casey, B. Cunningham, F. Dashe, J. Hoffman, B . Leveno, K (2014). Williams: Obstetrics. (24 ed.) New York: McGraw-Hill

4.Böhm M. De Backer, G. Christiaens, T. Cifkova, R. Galderisi, M. Dominiczak, A... (2013) Hipertensión y Riesgo Cardiovascular: Guia Practica para el manejo de la Hipertensión Arterial. 30 (3) 1-91.

5.Braunwald, E. Bonow, R. Mann, D. Libby, P. Zipes, D ( 2015). Braunwald: Tratado de cardiologia.(10 ed. ) España: Elsevier.

6.Cáparros, M. ( 2010) Actualizaciones: Hipertensión Arterial Durante el Embarazo y el Puerperio. 17 (7), 460-465

7.DeCherney, A . Laufer,N. Nathan, L. \& Roman, A. ( 2014). Diagnóstico y tratamiento ginecoobstetricos (11 $1^{\mathrm{a}}$ ed.). Mexico D.F : Mc Graw Hill

8.Driscoll, D. Gabbe, S. Galan, H. Jauniaux, E. Landon, M. Niebyl, J. \& Simpson, J.(2012) Obstetrics : Normal and problem pregnancies (6 $6^{\mathrm{a}}$ ed. ) Philadelphia: Elsevier- Saunders.

9.Markenson, G. Solomon, C. Pekow, P. \& Turzanski, R. ( 2009) Obstetrics: Prepregnacy and body mass index, gestacional weight gain and risk of hypertensive pregnancy among Latina women . 200 (167) e1-e7

10.Martel, N ( 2011). Hipertensión y Riesgo Cardiovascular: Hipertension y embarazo. 28( 5-6) . 167- 168.

11.Raman, M. ( 2016). Poster Presentation / Pregnancy Hipertation: Decreased Posteror Gray Matter Volumes. 276

12.Walls, R. ( 2017) Rosens: Emergency Medicine ( $9^{\mathrm{a}}$ ed)

Filadelfia: Elsevier. 